\title{
Fundamentals of Silico-Ferrite of Calcium and Aluminium (SFCA) Iron Ore Sinter Bonding Phase Formation: Effects of Basicity and Magnesium on Crystallisation during Cooling
}

\author{
Nathan A. S. WEBSTER, ${ }^{1) *}$ Mark I. POWNCEBY, ${ }^{1)}$ Rachel PATTEL, ${ }^{1)}$ James R. MANUEL ${ }^{2)}$ and \\ Justin A. KIMPTON ${ }^{3)}$ \\ 1) CSIRO Mineral Resources, Private Bag 10, Clayton South, VIC, 3169 Australia \\ 2) CSIRO Mineral Resources, PO Box 883, Kenmore, QLD, 4069 Australia. \\ 3) Australian Synchrotron, 800 Blackburn Rd, Clayton, VIC, 3168 Australia.
}

(Received on August 20, 2018; accepted on September 25, 2018)

\begin{abstract}
The effects of basicity and Mg addition on the crystallisation during cooling of complex Ca-rich ferrite iron ore sinter bonding phases SFCA and Fe-rich SFCA was investigated using in situ synchrotron X-ray diffraction. In synthetic iron ore sinter mixtures, cooling of a high temperature ( $T=1623 \mathrm{~K}$ ) assemblage comprising magnetite and melt showed that decreasing basicity from B $=4.0$ to 3.0 and 2.5 resulted in the formation of a Fe-rich SFCA phase being suppressed, with SFCA being the only Ca-rich ferrite phase to form initially from the melt at $B=2.5$. Increasing the $\mathrm{Mg}$ concentration in the sinter mixtures to 1 and $3 \mathrm{wt} \% \mathrm{MgO}$ resulted in an overall suppression of the amount of Ca-rich ferrite phase formation. However, $\mathrm{Mg}$ addition caused the formation of Fe-rich SFCA to be favoured over SFCA, with SFCA not observed to form at all during cooling in the $3 \mathrm{wt} \% \mathrm{MgO}$ mixture. The absence of SFCA in the high-Mg experiment was rationalised on the basis that the Fe-rich SFCA structure accommodates more $\mathrm{Fe}^{2+}$ than the SFCA structure, thereby stabilising Fe-rich SFCA relative to SFCA through replacement substitution of $\mathrm{Fe}^{2+}$ by $\mathrm{Mg}^{2+}$. Observation of Fe-rich SFCA in sinter may be an indicator of localised high basicity, and/or, high Mg concentration, within a sinter blend.
\end{abstract}

KEY WORDS: iron ore sinter; in situ synchrotron X-ray diffraction; complex Ca-rich ferrite iron ore sinter bonding phases; SFCA; crystallisation during cooling; $\mathrm{CaO}: \mathrm{SiO}_{2}$ ratio; $\mathrm{Mg}$ addition.

\section{Introduction}

'SFCA' (Silico-Ferrite of Calcium and Aluminium) phases are key bonding materials within industrial iron ore sinter. ${ }^{1)}$ Sinter is utilised extensively worldwide in the production of steel from iron ore and iron ore sinter typically constitutes more than $60 \%$ of the ferrous burden in modern blast furnaces in Japan and most of the blast furnaces in Europe. ${ }^{2)}$ Increased understanding of (i) the compositional and thermal stability of SFCA phases, (ii) their formation mechanisms, and (iii) the effect of different processing parameters on (i) and (ii) has the potential to improve the efficiency of the sintering process by being better able to predict optimal sintering conditions required to produce high-quality product based on the chemical composition and physical characteristics of a given iron ore sinter blend.

The SFCA in iron ore sinter has been categorised in the scientific literature on the basis of composition, morphology and crystal structure into (i) a high-Fe, low-Si form called SFCA-I which has a characteristic platy (also described as acicular) morphology. ${ }^{3)}$ Mumme et al. $^{4)}$ reported that

* Corresponding author: E-mail: nathan.webster@csiro.au DOI: https://doi.org/10.2355/isijinternational.ISIJINT-2018-573 an SFCA-I phase in industrial sinter contained 84 mass $\%$ $\mathrm{Fe}_{2} \mathrm{O}_{3}, 13$ mass $\% \mathrm{CaO}, 1$ mass $\% \mathrm{SiO}_{2}$ and 2 mass $\% \mathrm{Al}_{2} \mathrm{O}_{3}$, and also synthesised Si-free SFCA-I material which had the composition 83.2 mass $\% \mathrm{Fe}_{2} \mathrm{O}_{3}, 12.6$ mass $\% \mathrm{CaO}$ and 4.2 mass $\% \mathrm{Al}_{2} \mathrm{O}_{3}$. Sasaki and Hida determined that acicular calcium ferrite - which we consider to be equivalent to SFCA-I - does not form via crystallisation from melt during cooling; ${ }^{5)}$ and (ii) a low-Fe form called SFCA which is described as having a prismatic or columnar morphology. SFCA found in industrial sinters typically contains 60-76 mass $\% \mathrm{Fe}_{2} \mathrm{O}_{3}, 13-16$ mass $\% \mathrm{CaO}, 3-10$ mass $\% \mathrm{SiO}_{2}, 4-10$ mass $\% \mathrm{Al}_{2} \mathrm{O}_{3}$ and $0.7-1.5$ mass $\% \mathrm{MgO} .^{6,7)}$ Patrick and Pownceby ${ }^{8)}$ systematically resolved the equilibrium solid solution range and thermal stability of SFCA within the quaternary system $\mathrm{Fe}_{2} \mathrm{O}_{3}-\mathrm{CaO}-\mathrm{SiO}_{2}-\mathrm{Al}_{2} \mathrm{O}_{3}$ in air in the range $1513 \mathrm{~K}$ to $1663 \mathrm{~K}$. It should be noted that differentiation of SFCA-I and SFCA based on what may be an oversimplified morphological description of the two phases may be problematic, and the authors consider that differentiation should be made based on diffraction and/or compositional data.

An additional phase, referred to as Fe-rich SFCA, was identified by Webster et al. ${ }^{9)}$ This phase was observed during in situ X-ray diffraction (XRD) studies where the temperature reached $1623 \mathrm{~K}$, resulting in a large amount of 
melt formation and a final high temperature phase assemblage consisting of magnetite + melt. During subsequent cooling and melt crystallisation the occurrence of the previously unknown Fe-rich SFCA phase was revealed (Fig. 1). Figure 2(a) is a backscattered electron micrograph showing Fe-rich SFCA in a synthetic sample prepared by quenching from $1488 \mathrm{~K}$ while cooling under an oxygen partial pressure $\left(\mathrm{pO}_{2}\right)$ of $5 \times 10^{-3}$ atm. $\left.{ }^{9}\right)$ Quantitative electron probe microanalysis (EPMA) gave an average composition of 84.2 mass $\% \mathrm{Fe}_{2} \mathrm{O}_{3}, 9.6$ mass $\% \mathrm{CaO}, 1.8$ mass $\% \mathrm{SiO}_{2}$ and 5.7 mass $\% \mathrm{Al}_{2} \mathrm{O}_{3}$, indicating it is distinct from SFCA-I and SFCA. ${ }^{9)}$ Figure 3 shows laboratory XRD data collected for this quenched synthetic sample; the absence of the characteristic SFCA-I peaks at d-spacing $=10.7$ and $9.7 \AA(9.6$ and $10.6^{\circ} 2 \theta$ ), and the characteristic SFCA peaks at d-spacing $=8.2$ and $7.6 \AA\left(12.5\right.$ and $\left.13.6^{\circ} 2 \theta\right)$, further demonstrate that Fe-rich SFCA is distinct from SFCA-I and SFCA.

It is not known whether this Fe-rich SFCA phase is pres-
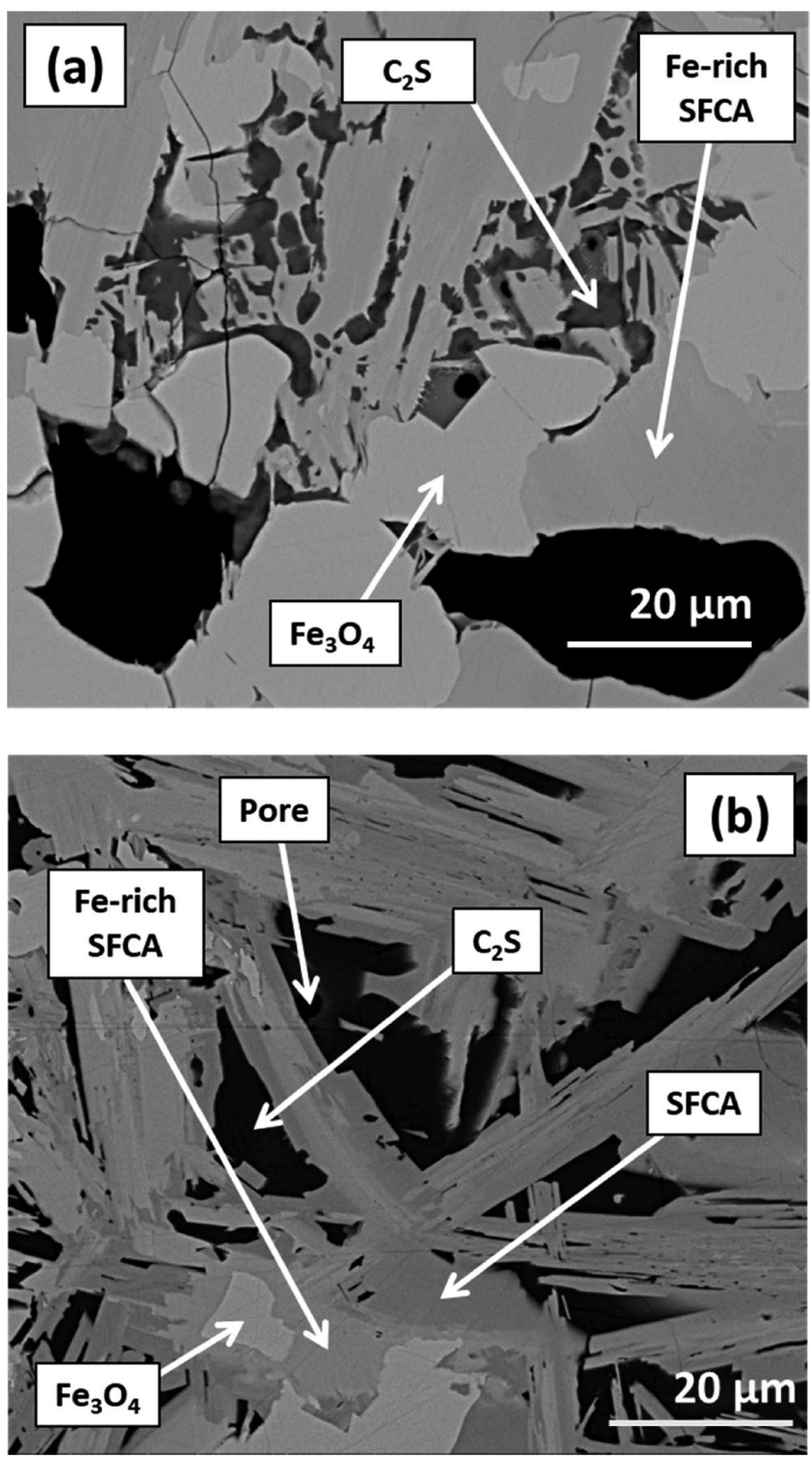

Fig. 2. Backscattered electron micrographs collected for (a) a synthetic sample, quenched from $1488 \mathrm{~K}$ during cooling at $\mathrm{pO}_{2}=5 \times 10^{-3} \mathrm{~atm}$, showing the Fe-rich SFCA phase, $\left.{ }^{9}\right)$ and (b) a pot-grate sinter sample showing association of SFCA, Fe-rich SFCA and $\mathrm{Fe}_{3} \mathrm{O}_{4}$ (magnetite) phases. $\mathrm{C}_{2} \mathrm{~S}=$ $2 \mathrm{CaO} . \mathrm{SiO}_{2}{ }^{10)}$ ent in industrial iron ore sinter. However, a similar phase has been observed in pot-grate sinter - with bulk composition 59.00 mass $\%$ T-Fe, 8.30 mass $\% \mathrm{CaO}, 5.24$ mass $\%$ $\mathrm{SiO}_{2}, 1.64$ mass $\% \mathrm{Al}_{2} \mathrm{O}_{3}$ and 1.16 mass $\% \mathrm{MgO}$ - produced in CSIRO's facility in Pullenvale (Fig. 2(b)). ${ }^{10)}$ The potgrate Fe-rich SFCA had average composition 84.8 mass $\%$ $\mathrm{Fe}_{2} \mathrm{O}_{3}, 9.4$ mass \% CaO, 2.2 mass $\% \mathrm{SiO}_{2}, 2.8$ mass $\% \mathrm{Al}_{2} \mathrm{O}_{3}$ and 1.8 mass $\% \mathrm{MgO}$, which was close to the composition observed in the synthetic material but with $\mathrm{Mg}$ present as an impurity (from the dolomite flux).

EPMA oxide totals for the Fe-rich SFCA phase were $\sim 101$ mass $\%$, an indication that the phase contains $\mathrm{Fe}^{2+}$ in addition to the $\mathrm{Fe}^{3+}$ (i.e., the EPMA data were calculated assuming all $\mathrm{Fe}$ was present as $\mathrm{Fe}^{3+}$. Totals of $>100 \%$ indicate the presence of some $\mathrm{Fe}$ as $\mathrm{Fe}^{2+}$ ). The SFCA present in Fig. 2(b) had an average composition of 72.7 mass $\%$ $\mathrm{Fe}_{2} \mathrm{O}_{3}, 15.3$ mass $\% \mathrm{CaO}, 8.2$ mass $\% \mathrm{SiO}_{2}, 3.6$ mass $\% \mathrm{Al}_{2} \mathrm{O}_{3}$ and 0.7 mass $\% \mathrm{MgO}$ (total $=100.4$ mass $\%$, with most $\mathrm{Fe}$ present therefore as $\mathrm{Fe}^{3+}$ ), and the $\mathrm{Fe}_{3} \mathrm{O}_{4}$ had average composition 96.6 mass $\% \mathrm{Fe}_{2} \mathrm{O}_{3}, 1.9$ mass $\% \mathrm{CaO}, 0.9$ mass $\%$ $\mathrm{Al}_{2} \mathrm{O}_{3}$ and 2.6 mass $\% \mathrm{MgO}$ (total $=102.1 \mathrm{mass} \%$, indicating the $\mathrm{Fe}^{2+}$ content is greater than in the Fe-rich SFCA). The Fe-rich SFCA, therefore, appears to be an intermediate phase between $\mathrm{Fe}_{3} \mathrm{O}_{4}$ and SFCA in terms of composition. The Fe-rich SFCA phase in Fig. 2(b) did not appear to be significantly texturally different from the SFCA.

A number of recent investigations ${ }^{9,11-19)}$ have utilised in situ XRD in order to establish the formation mechanisms of SFCA phases under simulated sintering conditions from synthetic starting sinter mixtures in the range 298-1 $623 \mathrm{~K}$, under oxygen partial pressures $\left(\mathrm{pO}_{2}\right)$ in the range 0.21 to $1 \times 10^{-4} \mathrm{~atm}$, and at basicity $\left(\mathrm{B},=\mathrm{CaO}: \mathrm{SiO}_{2}\right)$ values in the range $2.5-5$. Regarding basicity, Webster at al. ${ }^{15}$ established the following as it relates to SFCA and SFCA-I phase formation during heating; increasing basicity significantly increased the thermal stability range of SFCA-I, from $1363 \mathrm{~K}$ to $1533 \mathrm{~K}$ for a mixture with $\mathrm{B}=2.5$, to $\sim 1323 \mathrm{~K}$ to 1593 at $\mathrm{B}=5$. Increasing basicity also increased the

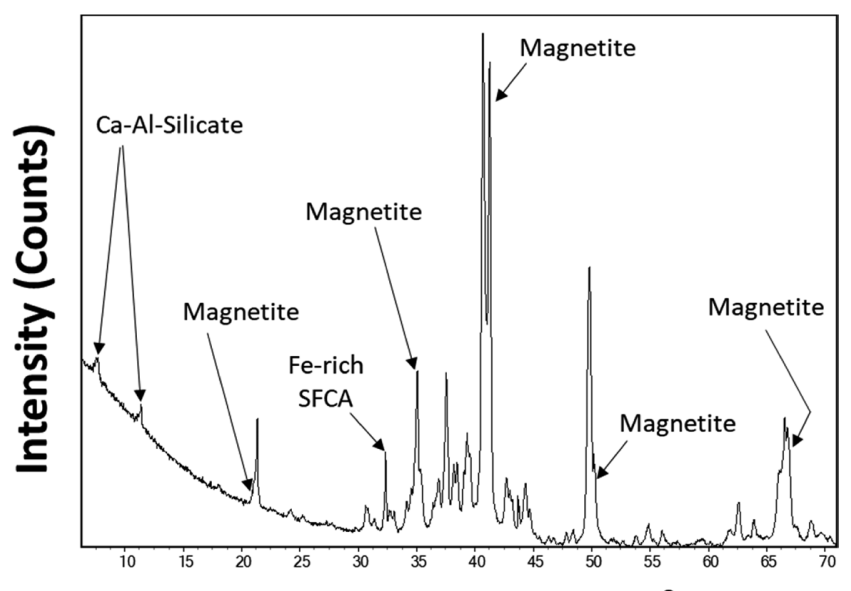

$2 \theta$ (degrees, $\lambda=1.789 \AA$ )

Fig. 3. Laboratory XRD data collected for the synthetic material for which a backscattered electron micrograph is shown in Fig. 2(a). The characteristic Fe-rich SFCA peak at $\mathrm{d}$-spacing $=3.2 \AA\left(32.5^{\circ} 2 \theta\right)$ is labelled. Also labelled are magnetic peaks, and peaks matched with a Ca-Al-silicate phase (Internal Centre of Diffraction Data entry no. 01-088-1797). 
amount of SFCA-I formed, from 18 mass $\%$ for the mixture with $\mathrm{B}=2.5$ to 25 mass $\%$ for the $\mathrm{B}=5$ mixture. There was a corresponding decrease in the amount of SFCA which formed from $\mathrm{B}=2.5$ to $\mathrm{B}=5$. In another of these investigations the effect of $\mathrm{Al}_{2} \mathrm{O}_{3}$ concentration (with $\mathrm{B}=4$ ) on the crystallisation of Fe-rich SFCA and SFCA was established. ${ }^{9)}$ Increasing the $\mathrm{Al}_{2} \mathrm{O}_{3}$ content (i) increased the temperature at which both the Fe-rich SFCA and SFCA phases crystallised from the melt, and (ii) decreased the range of temperature over which Fe-rich SFCA exists before the SFCA phase formed. Whilst the effects of alumina on the formation of Fe-rich SFCA and SFCA during cooling have been established, the effect of basicity on the crystallisation of Fe-rich SFCA and SFCA has not been investigated. Establishing the effects of basicity is the first aim of this paper.

The Fe-rich SFCA phase present in Fig. 2(b) contained $\mathrm{Mg}$, and dolomite, $(\mathrm{Ca}, \mathrm{Mg}) \mathrm{CO}_{3}$, and other $\mathrm{MgO}$-bearing materials such as olivine, $(\mathrm{Fe}, \mathrm{Mg})_{2} \mathrm{SiO}_{4}$, and serpentine, $(\mathrm{Mg}, \mathrm{Fe})_{3} \mathrm{Si}_{2} \mathrm{O}_{5}(\mathrm{OH})_{4}$, are commonly used in addition to limestone, $\mathrm{CaCO}_{3}$, as flux components for the production of iron ore sinters. ${ }^{20)}$ The $\mathrm{MgO}$ content of the resulting sinter gives blast furnace slag good flowability and desulphurisation properties, ${ }^{6}$ and the addition of up to 3 mass $\% \mathrm{MgO}$ to sinter feed is typical. The second aim of this paper is to determine the effects of $\mathrm{Mg}$ on the crystallisation of Fe-rich SFCA and SFCA during cooling of Mg-doped sinter. We have chosen to focus on the cooling since the effects of $\mathrm{Mg}$ addition on phase behavior during heating - overall suppression of complex calcium ferrite formation and the expense of magnesio-ferrite, but with $\mathrm{Mg}$ favouring the formation of SFCA-I relative to SFCA - are well established. ${ }^{20-22)}$

\section{Experimental}

\subsection{In situ XRD Sample Preparation}

Table 1 shows the concentration of each mixture, in terms of mass $\%$ of oxides. The base mixture, SM4/5, with $\mathrm{B}=4.0$ and containing $5 \mathrm{wt} \% \mathrm{Al}_{2} \mathrm{O}_{3}$ has been utilised in a number of our previous investigations. ${ }^{9,13-19)}$ The SM3/5 and SM2.5/5 mixtures, with $\mathrm{B}=3.0$ and 2.5 , respectively, were designed to examine the effect of basicity. The $\mathrm{SM} 4 / 5-1 \mathrm{MgO}$ and $3 \mathrm{MgO}$ mixtures, with 1 and $3 \mathrm{wt} \%$ addition of $\mathrm{MgO}$ to $\mathrm{SM} 4 / 5$, respectively, were designed to examine the effect of $\mathrm{Mg}$ concentration. The mixtures were prepared from fine grained synthetic hematite, $\mathrm{Fe}_{2} \mathrm{O}_{3}$ (Acros Organics, 99.999\%); calcite, $\mathrm{CaCO}_{3}$ (Thermo Fisher, 99.95\%); quartz, $\mathrm{SiO}_{2}$ (Sigma Aldrich, 99.995\%); gibbsite, $\mathrm{Al}(\mathrm{OH})_{3}$ (Alcan OP25 Super White, 99.9\%); and magne-

Table 1. Nominal compositions, in mass $\%$ oxides, of the mixtures used in the in situ S-XRD experiments.

\begin{tabular}{lcccccc}
\hline \multirow{2}{*}{ Sample } & \multicolumn{5}{c}{ Concentration (oxide mass\%) } & \multirow{2}{*}{ Basicity } \\
\cline { 2 - 6 } & $\mathrm{Fe}_{2} \mathrm{O}_{3}$ & $\mathrm{CaO}$ & $\mathrm{SiO}_{2}$ & $\mathrm{Al}_{2} \mathrm{O}_{3}$ & $\mathrm{MgO}$ & \\
\hline $\mathrm{SM} 4 / 5$ & 77.36 & 14.08 & 3.56 & 5.00 & & 4.0 \\
$\mathrm{SM} 3 / 5$ & 73.78 & 15.87 & 5.35 & 5.00 & & 3.0 \\
$\mathrm{SM} 2.5 / 5$ & 70.20 & 17.67 & 7.13 & 5.00 & & 2.5 \\
$\mathrm{SM} 4 / 5-1 \mathrm{MgO}$ & 76.59 & 13.94 & 3.52 & 4.95 & 1.00 & 4.0 \\
$\mathrm{SM} 4 / 5-3 \mathrm{MgO}$ & 75.04 & 13.66 & 3.45 & 4.85 & 3.00 & 4.0 \\
\hline
\end{tabular}

site, $\mathrm{MgCO}_{3}$ (99.9\%). Weighed powders were micronised in ethanol for $4 \mathrm{~min}^{-1}$, centrifuged and dried at $333 \mathrm{~K}$ overnight. They were then remixed by hand in a mortar and pestle to ensure homogeneity.

\subsection{In situ XRD Experimentation and Data Analysis}

In situ synchrotron XRD (S-XRD) experiments were performed on the powder diffraction beamline at the Australian Synchrotron. ${ }^{23)}$ An Anton Paar HTK 2000 high-temperature chamber employing a Pt resistance strip heater was fitted to the beamline. XRD data were collected over the range $5^{\circ} \leq$ $2 \theta \leq 85.5^{\circ}$ continuously throughout heating, with individual datasets collected for $24 \mathrm{sec}$, using an X-ray wavelength of $1.1061 \AA$ calibrated using LaB6 (NIST 660b line position standard).

For each in situ experiment a heating rate of $50 \mathrm{~K} \mathrm{~min}^{-1}$ was used from 298-1 $623 \mathrm{~K}$. The rate was then reduced to $5 \mathrm{~K} \mathrm{~min}^{-1}$ during cooling between $1623-1273 \mathrm{~K}$, and then increased to $50 \mathrm{~K} \mathrm{~min}^{-1}$ from 1273 to $298 \mathrm{~K}$. The temperature was measured by a Pt/PtRh10\% thermocouple connected to the underside of the platinum strip directly underneath the sample. The time-temperature profile used for these experiments, especially during cooling, is significantly slower than those encountered in industrial sintering. It was chosen so as to monitor phase crystallisation with reasonable temperature resolution in order to establish trends with compositional variation.

The temperatures of phase formation/transformation given throughout the manuscript are those at the start - which is when the temperatures were automatically recorded - of the relevant data set. An error of $\pm 10 \mathrm{~K}$ is assigned to these values consistent with previous work. ${ }^{9)}$

The decomposition of precursor phases and the formation of new phases as the experiments progressed was visualised by stacking the datasets to produce plots of accumulated data with temperature plotted vs $2 \theta$, viewed down the intensity axis.

Throughout heating and cooling the Anton Paar chamber was fed by a continuous flow of a $0.5 \% \mathrm{O}_{2}$ in $\mathrm{N}_{2}$ gas mixture $\left(\mathrm{pO}_{2}=5 \times 10^{-3} \mathrm{~atm}\right)$. Hsieh and Whiteman concluded that this $\mathrm{pO}_{2}$ maximised the formation of Ca-rich ferrites while still producing mineral assemblages similar to those found in industrial sinters. ${ }^{24)}$

\section{Results and Discussion}

Figure 4 shows a plot of accumulated in situ XRD data, viewed down the intensity axis and with temperature plotted vs $2 \theta$, for the experiment performed for SM4/5-1MgO mixture. During heating the sequence of phase decomposition/formation events were as follows: decomposition of $\mathrm{Al}(\mathrm{OH})_{3}$; decomposition of $\mathrm{MgCO}_{3}$; decomposition of $\mathrm{CaCO}_{3}$; formation of lime $(\mathrm{CaO})$; formation of dicalcium ferrite $\left(\mathrm{C}_{2} \mathrm{~F}\right.$, i.e. $\left.2 \mathrm{CaO} . \mathrm{Fe}_{2} \mathrm{O}_{3}\right)$; formation of calcium ferrite (CF, i.e. $\mathrm{CaO} \cdot \mathrm{Fe}_{2} \mathrm{O}_{3}$ ); formation of SFCA-I; and formation of SFCA. At the peak temperature the phase assemblage was $\mathrm{Fe}_{3} \mathrm{O}_{4}$ in a $\mathrm{FeO}-\mathrm{Fe}_{2} \mathrm{O}_{3}-\mathrm{CaO}-\mathrm{Al}_{2} \mathrm{O}_{3}-\mathrm{SiO}_{2}$ melt. During cooling the Fe-rich SFCA began to crystallise from the melt at $1506 \mathrm{~K}$, followed by SFCA at $1481 \mathrm{~K}$. Secondary $\mathrm{Fe}_{2} \mathrm{O}_{3}$ was observed to form below $1393 \mathrm{~K}$. Table 2 shows the temperatures of Fe-rich SFCA and SFCA formation during 
cooling for each mixture. The results for SM4/5 are in good agreement with those determined previously. ${ }^{9}$

In terms of the crystallisation temperature of the Fe-rich

Table 2. Temperatures of the Fe-rich SFCA and SFCA crystallisation events during cooling.

\begin{tabular}{lcc}
\hline \multirow{2}{*}{ Sample } & \multicolumn{2}{c}{ Temperature (K) } \\
\cline { 2 - 3 } & Fe-rich SFCA & SFCA \\
\hline $\mathrm{SM} 4 / 5$ & 1489 & 1475 \\
$\mathrm{SM} 3 / 5$ & 1501 & 1496 \\
$\mathrm{SM} 2.5 / 5$ & 1484 & 1484 \\
$\mathrm{SM} 4 / 5-1 \mathrm{MgO}$ & 1506 & 1481 \\
$\mathrm{SM} 4 / 5-3 \mathrm{MgO}$ & 1443 & - \\
\hline
\end{tabular}

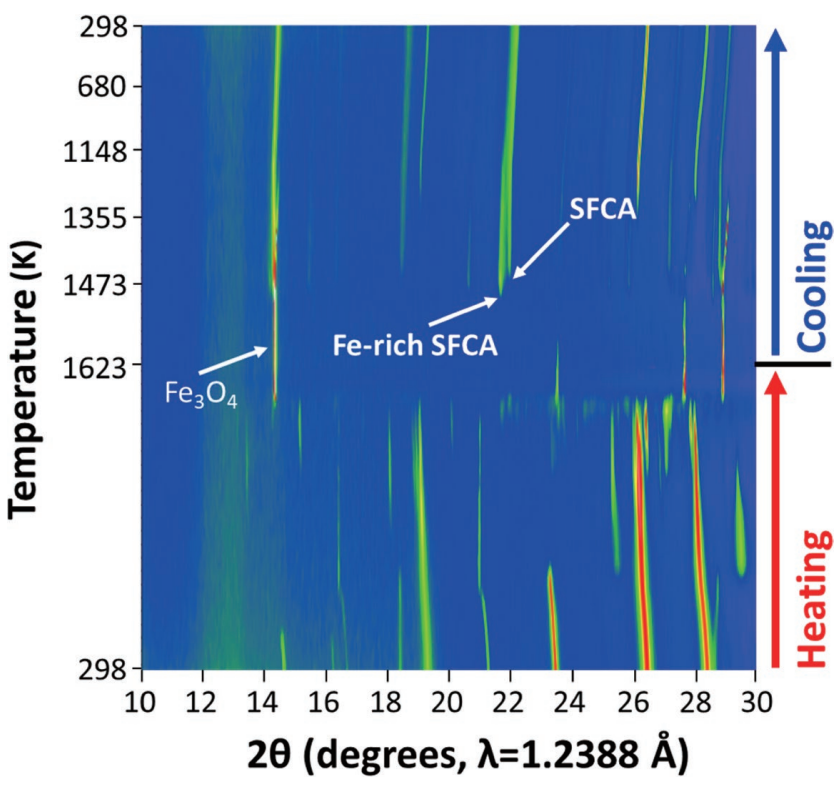

Fig. 1. In situ S-XRD data showing the formation of Fe-rich SFCA and SFCA during cooling from a magnetite + melt phase assemblage at $1623 \mathrm{~K}$ and $\mathrm{pO}_{2}=5 \times 10^{-3}$ atm in a synthetic iron ore sinter mixture. Adapted from Ref. (9).

(a)

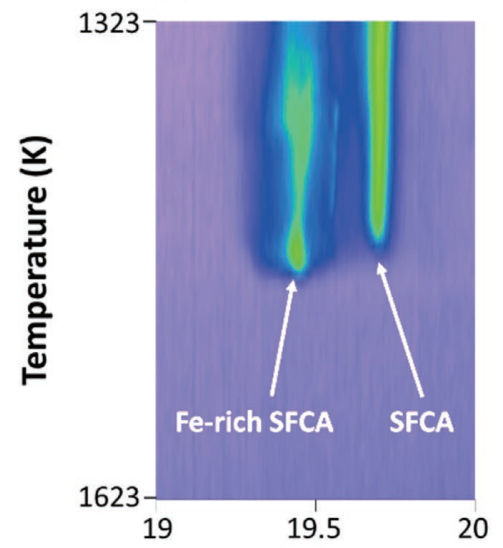

(b)

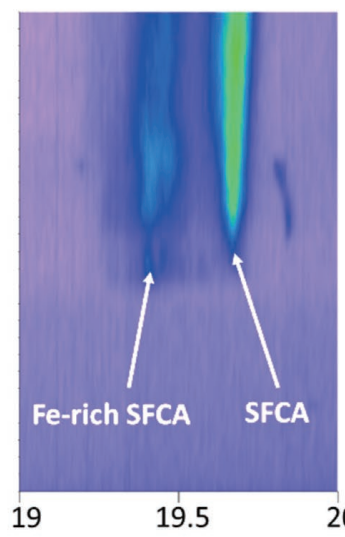

SFCA and SFCA phases in Table 2, there does not appear be a significant variation with basicity given the $\pm 10 \mathrm{~K}$ uncertainty assigned to temperature values. There was, however, a suppression in the formation of the Fe-rich SFCA phase with decreasing basicity (Fig. 5), with only a very small amount of the Fe-rich SFCA phase observed for the $\mathrm{B}=2.5$ mixture (Fig. 5(c)). There was also a reduction, with decreasing basicity, of the temperature range where Ferich SFCA was present before SFCA began to form, with both phases forming simultaneously during cooling at $\mathrm{B}=$ 2.5. We note that the basicity of the Fe-rich SFCA phases discussed in Section 1 was high - in the range $\mathrm{B}=4.3$ to 5.3 - and so it is not surprising that a higher basicity in the reacting mixture would promote the formation of the Fe-rich SFCA phase.

Increasing $\mathrm{Mg}$ concentration up to $3 \mathrm{wt} \% \mathrm{MgO}$ for the $\mathrm{SM} 4 / 5-3 \mathrm{MgO}$ mixture lowered the crystallisation temperature of Fe-rich SFCA significantly, while SFCA was not

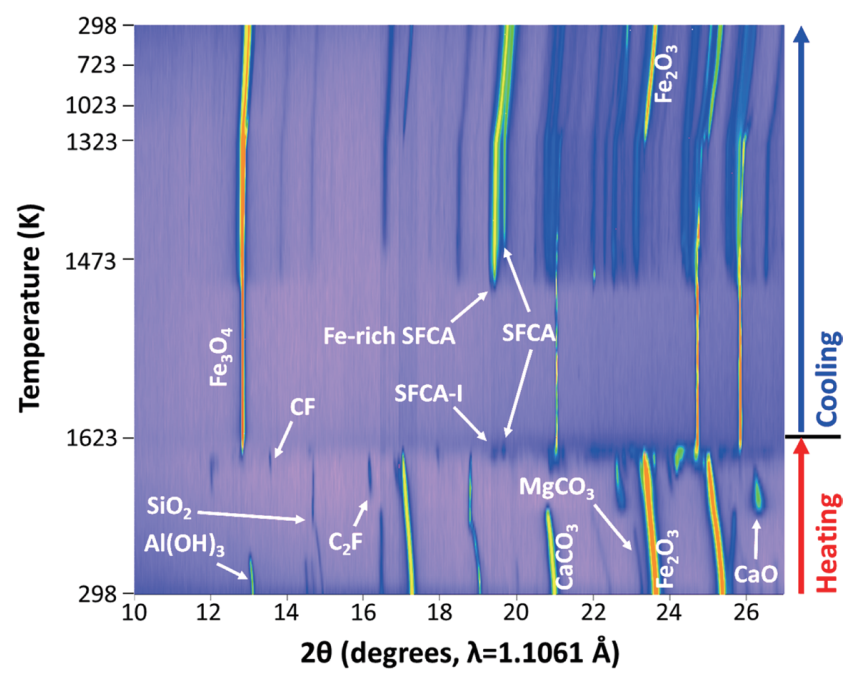

Fig. 4. In situ $\mathrm{S}-\mathrm{XRD}$ data collected for the $\mathrm{SM} 4 / 5-1 \mathrm{MgO}$ sample, viewed down the intensity axis, during heating and cooling in the range $298-1623 \mathrm{~K}$ and at $\mathrm{pO}_{2}=5 \times 10^{-3} \mathrm{~atm}$. $\mathrm{CF}=\mathrm{CaO} . \mathrm{Fe}_{2} \mathrm{O}_{3}, \mathrm{C}_{2} \mathrm{~F}=2 \mathrm{CaO} . \mathrm{Fe}_{2} \mathrm{O}_{3}$.

(c)

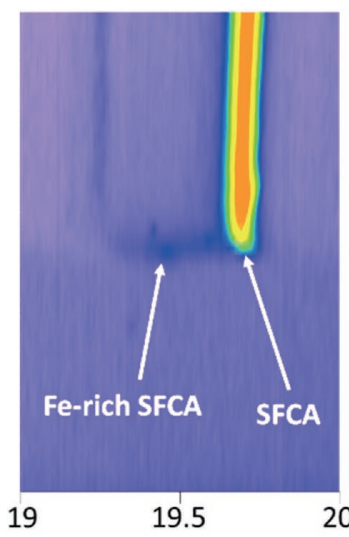

(d)

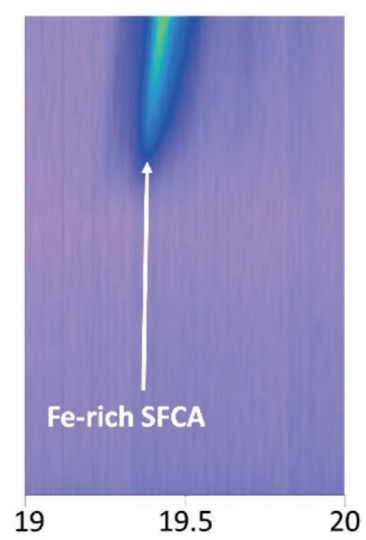

\section{$2 \theta$ (degrees, $\lambda=1.1061 \AA ̊)$}

Fig. 5. In situ S-XRD data collected between 1623 and $1323 \mathrm{~K}$ during cooling and over the range $19^{\circ}<2 \theta<20^{\circ}$ for the (a) SM4/5, (b) SM3/5, (c) SM2.5/5 and (d) SM4/5-3MgO mixtures. The colours in the plots are proportional to $\mathrm{X}$-ray intensity, with red more intense than green, and green more intense than blue. 


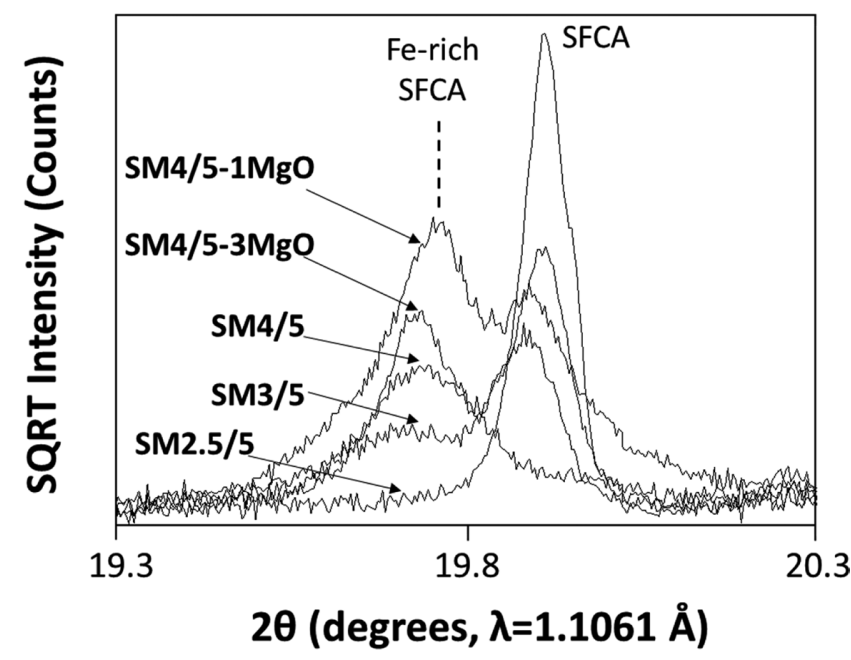

Fig. 6. In situ $\mathrm{S}-\mathrm{XRD}$ data collected over the range $19^{\circ}<2 \theta<$ $20^{\circ}$ at $298 \mathrm{~K}$ for the SM4/5, SM3/5, SM2.5/5, SM4/5$1 \mathrm{MgO}$ and $\mathrm{SM} 4 / 5-3 \mathrm{MgO}$ mixtures.

observed to crystallise during cooling in this experiment (Fig. 5(d)). The general suppression of complex Ca-rich ferrite phase formation (i.e. SFCA phases) with increasing $\mathrm{Mg}$ content is consistent with previous work. ${ }^{20,21)}$ The presence of $\mathrm{Mg}$ here also favoured the formation of Fe-rich SFCA compared to SFCA, in a similar manner to the presence of $\mathrm{Mg}$ favouring the formation of SFCA-I compared to SFCA during heating. ${ }^{22)}$ Considering the sizes of the $\mathrm{Mg}^{2+}$ and $\mathrm{Fe}^{2+}$ cations $\left(0.86\right.$ and $0.92 \AA$ for $\mathrm{Mg}^{2+}$ and $\mathrm{Fe}^{2+}$ in octahedral coordination, respectively ${ }^{25)}$, and the significantly larger size of the $\mathrm{Ca}^{2+}$ cation $(1.16 \AA)$, we postulate that $\mathrm{Mg}$ substitutes for $\mathrm{Fe}^{2+}$ in the Fe-rich SFCA and SFCA crystal structures. A greater solubility of $\mathrm{Mg}$ in Fe-rich SFCA, as evidenced by the formation of this phase being favoured over SFCA as Mg content increases, is consistent with this phase incorporating a higher proportion of $\mathrm{Fe}^{2+}$ (see Section 1). Figure 6 shows that for each mixture that the Fe-rich SFCA phase formed, the characteristic peak of Fe-rich SFCA at $19.7^{\circ} 2 \theta(\mathrm{d}$-spacing $=3.2 \AA)$ was observed down to $298 \mathrm{~K}$.

\section{Conclusion}

The effects of basicity and $\mathrm{Mg}$ concentration on the crystallisation of Fe-rich SFCA and SFCA phases during cooling of iron ore sinter mixtures heated and cooled in the range $298-1623 \mathrm{~K}$ and at $\mathrm{pO}_{2}=5 \times 10^{-3}$ atm have been investigated using in situ S-XRD. Decreasing basicity from $\mathrm{B}=4.0$ to 2.5 resulted in the formation of a Fe-rich SFCA phase being suppressed, with SFCA becoming the only Ca-rich ferrite phase to crystallise from the melt during cooling at $\mathrm{B}=2.5$. An opposing effect was observed with increasing $\mathrm{Mg}$ addition, with $\mathrm{Mg}$ stabilising Fe-rich SFCA relative to SFCA.

It is unknown whether Fe-rich SFCA is observed in industrial sinter. However, given that industrial sinter blends are typically fluxed to basicity $<2.0$, any observation via electron microscopy of the Fe-rich SFCA phase in industrial or pilot scale pot-grate sinter may be an indicator of localised high basicity, and/or, localised high $\mathrm{Mg}$ concentration in a sinter blend.
Future work will investigate the effect of Ti content on the crystallisation of Fe-rich SFCA and SFCA during cooling, since the introduction of a minor amount of titanium-bearing sinter into the blast furnace burden is a strategy used by steelmakers to extend blast furnace operating campaigns. $\left.{ }^{26}\right)$ Given that it has been previously shown that the SFCA crystal structure can accommodate more Ti than the SFCAI crystal structure, ${ }^{17)}$ it is hypothesised here that increasing Ti content will suppress Fe-rich SFCA formation relative to SFCA formation during cooling. Future work could also investigate the effect of cooling rate on the formation of the Fe-rich SFCA and SFCA phases.

Regardless of whether or not Fe-rich SFCA is actually present in industrial sinter, this study progresses the fundamental knowledge of iron ore sintering reactions, since Fe-rich SFCA may form as an intermediate phase during cooling even if it is not preserved in cooled sinter product.

\section{Acknowledgements}

This research was undertaken on the powder diffraction beamline (10BM1) at the Australian Synchrotron (part of ANSTO), Victoria, Australia, under beamtime award AS182/PD/13350.

\section{REFERENCES}

1) I. Tonžetć and A. Dippenaar: Miner. Eng., 24 (2011), 1258.

2) L. Lu and O. Ishiyama: Iron Ore: Mineralogy, Processing and Environmental Sustainability, Elsevier/Woodhead Publishing, Cambridge, (2015), 393.

3) J. McAndrew and J. M. F. Clout: Proc. 4th China-Australia Symp. on Technology of Feed Preparation for Ironmaking, MMI, HI, CSIRO, CSM, Dampier, Australia, (1993), 1.

4) W. G. Mumme, J. M. F. Clout and R. W. Gable: Neues Jahrb. Miner. Abh., 173 (1998), 93.

5) M. Sasaki and Y. Hida: Tetsu-to-Hagané, 68 (1982), 563.

6) J. Hancart, V. Leroy and A. Bragard: CNRM Metall. Rep., DS 24/67 (1967), 3.

7) S. N. Ashan, T. Mukkerjee and J. A. Whiteman: Ironmaking Steelmaking, 10 (1983), 54.

8) T. R. C. Patrick and M. I. Pownceby: Metall. Mater. Trans. B, 32 (2001), 1 .

9) N. A. S. Webster, M. I. Pownceby, I. C. Madsen and J. A. Kimpton: Metall. Mater. Trans. B, 43 (2012), 1344.

10) S. Nicol, J. Chen, M. I. Pownceby and N. A. S. Webster: ISIJ Int., 58 (2018), 2157

11) N. V. Y. Scarlett, M. I. Pownceby, I. C. Madsen and A. Christensen: Metall. Mater. Trans. B, 35 (2004), 929.

12) N. V. Y. Scarlett, I. C. Madsen, M. I. Pownceby and A. N. Christensen: J. Appl. Crystallogr., 37 (2004), 362.

13) N. A. S. Webster, M. I. Pownceby, I. C. Madsen and J. A. Kimpton: ISIJ Int., 53 (2013), 774

14) N. A. S. Webster, M. I. Pownceby and I. C. Madsen: ISIJ Int., 53 (2013), 1334.

15) N. A. S. Webster, M. I. Pownceby, I. C. Madsen, A. J. Studer, J. R. Manuel and J. A. Kimpton: Metall. Mater. Trans. B, 45 (2014), 2097.

16) N. A. S. Webster, M. I. Pownceby, I. C. Madsen, A. J. Studer and J. A. Kimpton: Powder Diffr., 29 (2014), S54.

17) N. A. S. Webster, J. G. Churchill, F. Tufaile, M. I. Pownceby, J. R. Manuel and J. A. Kimpton: ISIJ Int., 56 (2016), 1715.

18) N. A. S. Webster, D. P. O'Dea, B. G. Ellis and M. I. Pownceby: ISIJ Int., 57 (2017), 41.

19) N. A. S. Webster, M. I. Pownceby, R. Pattel and J. A. Kimpton: Powder Diffr., 32 (2017), S85.

20) C. E. Loo, L. C. Mackey and B. M. England: Trans. Inst. Min. Metall. C, 105 (1996), 175.

21) U. S. Yadav, B. D. Pandey, B. K. Das and D. N. Jena: Ironmaking Steelmaking, 29 (2002), 91.

22) M. I. Pownceby, N. A. S. Webster, J. R. Manuel and N. Ware: Miner. Process. Extr. Metall., 125 (2016), 140.

23) K. Wallwork, B. Kennedy and D. Wang: AIP Conf. Proc., 879 (2007), 879.

24) L.-H. Hsieh and J. A. Whiteman: ISIJ Int., 29 (1989), 24.

$25)$ R. Shannon: Acta Crystallogr. A, 32 (1976), 751

26) Y. Li, Y. Q. Li and R. J. Fruehan: ISIJ Int., 41 (2001), 1417. 